\title{
Knowledge and Attitudes of Preschool Teachers about Speech and Language Disorders in Turkey
}

\section{Ayşe Aydin Uysal ${ }^{1 \rtimes(D)}$ Ayşe Hicret Güdük² ${ }^{2}$ Gülşah Turas ${ }^{3}$}

${ }_{1,2, s}$ Faculty of Education, Kocaeli University, Turkey 'Email:ayse.uysal@kocaeli.edu.trTel:05077364715

EEmail:aysehicret.guduk@kocaeli.edu.trTel:05065090476

${ }^{s}$ Email: gulsah.tura@kocaeli.edu.trTel:05370565515

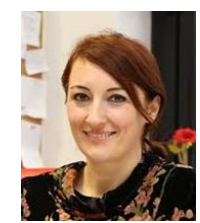

Corresponding Author

\begin{abstract}
The number of people with speech and language disorders is increasing every day (McLeod and McKinnon, 2007). Preschool teachers play a key role in diagnosing and treatment of these disorders since children acquire speech and language abilities rapidly in the preschool period. Speech and language therapy is a new discipline in Turkey. Therefore, the aim of this study is to determine the knowledge levels of preschool teachers in Turkey about children with speech and language disorders. The sample consisted of 153 preschool teachers from Kocaeli, Turkey and a self-administered Teacher Knowledge of Speech/Language Impairment Questionnaire was completed by the participants. Results revealed that knowledge and awareness levels of preschool teachers about children with speech/language impairment are limited. While $46 \%$ of the participants report that they have little or no experience with speech/language impaired children and do not feel themselves adequate in teaching children with severe language problems. Workshops designed for preschool teachers about speech and language disorders may offer opportunities to learn about the resources and classroom strategies that are proven successful in teaching students with speech and language disorders in Turkey.
\end{abstract}

Keywords: Speech, Language, Preschool teachers, Attitudes, Disorders, Early childhood.

Citation | Ayşe Aydin Uysal; Ayşe Hicret Güdük; Gülşah Tura (2019). Knowledge and Attitudes of Preschool Teachers about Speech and Language Disorders in Turkey. Asian Journal of Education and Training, 5(4): 562-568.

History:

Received: 12 August 2019

Revised: 16 September 2019

Accepted: 18 October 2019

Published: 9 December 2019

Licensed: This work is licensed under a Creative Commons

Attribution 3.0 License $(\mathrm{oc}) \mathbf{E Y}$

Publisher: Asian Online Journal Publishing Group
Acknowledgement: All authors contributed to the conception and design of the study.

Funding: This study was funded by the University of Kocaeli University Funding: This study was funded by the University of Kocaeli University
Faculty of Education Institutional Review Board (99332089/605.01/20020317). Institutional Review Boar Competing Interests: The authors declare that they have no conflict of interests.

Transparency: The authors confirm that the manuscript is an honest, accurate, and transparent account of the study was reported; that no vital features of the study have been omitted; and that any discrepancies from the study as planned have been explained.

Ethical: This study follows all ethical practices during writing.

\section{Contents}

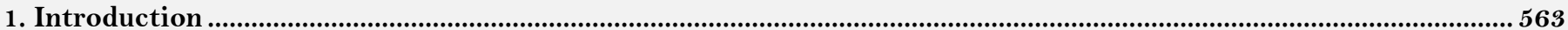

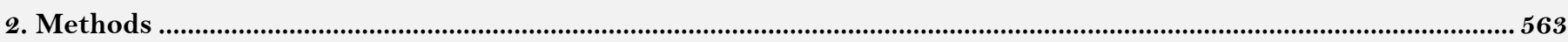

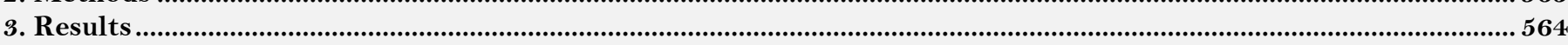

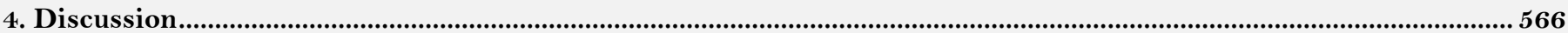

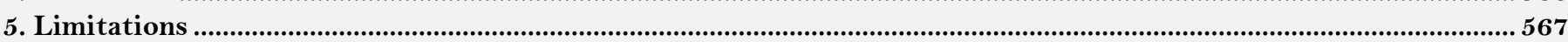

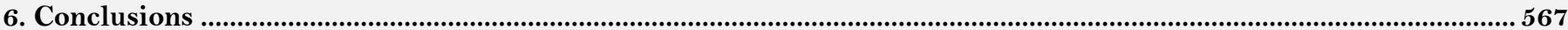

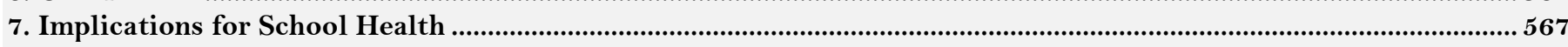

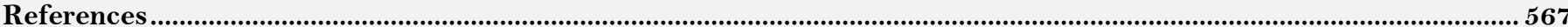




\section{Contribution of this paper to the literature}

This study contributes to existing literature by determining the knowledge levels of preschool teachers in Turkey about children with speech and language disorders.

\section{Introduction}

In the preschool years, children acquire speech and language abilities which allow them to engage in exchanges that lead to the acquisition of knowledge, development of thinking ability, improving interpersonal relationships and a sense of self (Committee on the Evaluation of the Supplemental Security Income (SSI) Disability Program for Children with Speech Disorders and Language Disorders, 2016).

Preschool age is the period in which vocabulary, syntax, morphology and pragmatic abilities develop and grow rapidly. In the first year, the child is expected to acquire his/her first words. In the second and third years, vocabulary increase very fast and use of different syntactic constructions and grammatical forms increase as well. In the fifth years, speech develops phonetically and grammatically in its basics and the child becomes able to communicate freely with the people (Conti-Ramsden and Durkin, 2012).

Speech and language disorders are among the most common developmental disorders in the preschool period (with a prevalence of $6 \%$ ). More than half of the children who have language delays between the age of 2 and 3 , recover spontaneously but the ones who have persistent speech and language delay may have problems in cognitive and social development, if they are not diagnosed and treated early (ASHA, 2018). Children with persistent speech and language disorders are reported to have difficulties in literacy and academic achievement throughout their school years (Felsenfeld et al., 1994). Speech and language disorders which have not been treated are also linked to the reading difficulties, Catts (1994); Lindsay and Dockrell (2000); Schuele (2004) educational underachievement (Snowling et al., 2001) and behavioral difficulties (Botting and Conti-Ramsden, 2000).

Researchers also confirm that early detection of speech and language disorders and treatment in the critical period lead to better overall outcomes (Law et al., 2000; Boyle et al., 2010). Preschool teachers play a key role in detecting children with speech and language disorders. Early detection of speech and language difficulties by preschool teachers, influence children's cognitive and psychosocial development and their academic achievement. Also, in therapy process, preschool teachers are one of the team members who should continuously be in contact with the speech and language therapists about the generalization of the learned abilities in the therapy settings and to prevent drop-outs (Blackorby and Wagner, 1996).

Speech-language pathology is a new area in Turkey. Although the number of graduate students in this area increases, there is still a need for preschool teachers to learn about this new profession and the distinctive role of SLT among the other professions in the treatment of speech and language disorders (Topbas, 2006).

The number of studies related to the knowledge levels of preschool teachers about speech and language disorders in Turkey is limited. Mavis et al. (2005) have conducted a study with 61 participants consisting of preschool and primary school teachers. In the study, more than half of the teachers state that speech and language disorders are byproducts of mental retardation, genetic problems or psychopathological problems. Moreover, most of them also add that these children can go to school but may have higher risks of learning disability. When their opinions about speech and language therapy are asked, they expressed that they believe in the helpful effects of speech and language therapy but they need to be informed about speech and language disorders. One of the possible reasons of this situation is not having lectures about these disorders in their educational background. In a study conducted by Aydın and Tura (2018) candidate teachers' knowledge levels about speech and language disorders are investigated and the findings reveal that candidate teachers received no or little lecture on speech and language disorders. So, when the critical role of preschool teachers before, during or after the therapy is taken into consideration, it is prominent to investigate the knowledge levels of preschool teachers about speech and language disorders.

Therefore, the aim of this study is to determine the knowledge levels of preschool teachers in Turkey about children with speech and language disorders.

\section{Methods}

This study is conducted with the intention of determining preschool teachers' knowledge and attitudes about children with speech and language disorders. In the study, descriptive survey model is used. While Karasar (2010) describes descriptive survey model as a study that aims to reveal a situation that exists at the present or at past, Buyukozturk et al. (2009) describes it as the studies that find out the participants' opinions, interests, talents, attitudes, etc. related to a situation or an event.

\subsection{Participants}

The population of the study consists of preschool teachers who work in preschool education institutions in Kocaeli province, İzmit district. Simple random sampling is used while determining the sample. In this sampling type, every item has the equal selection chance. ${ }^{17}$ Accordingly, the sampling of this study consists of 153 preschool teachers who work in private and public preschool education institutions in Kocaeli province, İzmit district. Data is acquired from the volunteer teachers that work in 20 different schools.

\subsection{Instrumentation}

"Teacher Knowledge of Speech/Language Impairment Questionnaire" that is developed by Sadler (2005) is used in the study. Sadler applies this questionnaire to 89 teachers who participate in a project work that continues three years in the northeast of England. The questionnaire's clarity rate is tested by applying it to five teachers before it is used in the study. The questionnaire, whose items are accepted as comprehensible by the teachers, is standardized for the main study. While some of the questions are closed ended, some of them consist of open-ended questions. In the questionnaire, there are items about teachers' knowledge levels of speech/language impairment, their education related to the topic, their preferred sources to increase and to update their knowledge and their 
attitudes towards the children with speech/language impairment in their classes, along with the teachers' personal information.

\subsection{Procedure}

After obtaining the required work permit from the Kocaeli Provincial Directorate of National Education, information related to the study is given by visiting the identified schools and by meeting with the headmasters. Questionnaires are given to the headmasters and they are received back after volunteer teachers fill them out.

\subsection{Data Analysis}

For the purpose of obtaining knowledge and attitudes related to children's speech language impairment from teachers who are working in preschool education institutions, frequency and percentage (\%) calculation is made with the SPSS 22 for Windows statistical package software. Within this scope, data is tabularized by making frequency and percentage calculation and interpreted later on.

\section{Results}

This part consists of information about the preschool teachers' educational background and their opinions about speech and language impairment. Almost all of the participant teachers are female (98.04\%). More than half of them have a bachelor's degree $(58,82 \%)$. According to their field of education, more than half of them are preschool teachers $(58.17 \%)$. Their total teaching experiences are between 5-10 years $(31.37 \%)$ and $10-15$ years (23.53\%). Their experiences with speech language impaired children are rare (35.95\%) and little (43.15\%) Table 1.

\begin{tabular}{|c|c|c|}
\hline Teachers $(n=153)$ & $\bar{f}$ & $\%$ \\
\hline \multicolumn{3}{|l|}{ Gender } \\
\hline Male & 3 & 1.96 \\
\hline Female & 150 & 98.04 \\
\hline \multicolumn{3}{|l|}{ Educational background } \\
\hline High school graduate & 24 & 15.69 \\
\hline Associate degree & 28 & 18.3 \\
\hline Bachelor's degree & 90 & 58.82 \\
\hline Master's degree & 11 & 7.19 \\
\hline \multicolumn{3}{|l|}{ Field of education } \\
\hline Preschool teaching & 89 & 58.17 \\
\hline Child development and education & 52 & 33.99 \\
\hline Special education & 2 & 1.31 \\
\hline Other & 10 & 6.53 \\
\hline \multicolumn{3}{|l|}{ Experience } \\
\hline $1-3$ years & 26 & 16.99 \\
\hline $3-5$ years & 17 & 11.11 \\
\hline $5-10$ years & 48 & 31.37 \\
\hline $10-15$ years & 36 & 23.53 \\
\hline $15-20$ years & 15 & 9.81 \\
\hline 20 years and above & 11 & 7.19 \\
\hline \multicolumn{3}{|l|}{ Experience with children with S/LI } \\
\hline Never & 16 & 10.45 \\
\hline Rare & 55 & 35.95 \\
\hline Little & 66 & 43.15 \\
\hline A great deal & 16 & 10.45 \\
\hline
\end{tabular}

Participant teachers in this study with regard to their existing knowledge about speech and language impaired students are also limited (63.40\%). Similarly, more than half of them find themselves partially sufficient $(58.17 \%)$ in meeting educational needs of speech language impaired students in their classes Table 2.

Table-2. Teacher's level of knowledge and confidence.

\begin{tabular}{l|c|c}
\hline Teachers $(\mathbf{n}=\mathbf{1 5 3})$ & $\mathbf{f}$ & $\mathbf{\%}$ \\
\hline Knowledge level of S/LI & & \\
\hline Very limited & 15 & 9.80 \\
\hline Limited & 97 & 63.40 \\
\hline Adequate & 39 & 25.49 \\
\hline A great deal & 2 & 1.31 \\
\hline Confidence level of meeting educational needs of students with S/LI & & \\
\hline Not at all confident & 16 & 10.46 \\
\hline Not very confident & 89 & 58.17 \\
\hline Reasonably confident & 43 & 28.10 \\
\hline Very confident & 5 & 3.27 \\
\hline
\end{tabular}

As it is seen in Table 3 while $50.98 \%$ of the participant teachers indicate that they received education on speech language disorders at the beginning of their teacher training, $40.02 \%$ of them indicate that they have not received any courses on this topic. While $52.57 \%$ of the teachers expressed to have an adequate training meeting their needs, $47.43 \%$ of them regard it as inadequate. 31.61 of participant teachers indicate that they increased their knowledge level on speech and language disorders with meeting these children in their class. They also state that 
they increased their knowledge levels by reading books about speech and language disorders $(24.40 \%)$ and via tv/media (19.94\%).

Table-3. Sources of teacher knowledge on speech/language impairment.

\begin{tabular}{l|c|c}
\hline Teachers (n=153) & f & \% \\
\hline During initial teacher training & & \\
\hline Yes & 78 & 50.98 \\
\hline No & 75 & 49.02 \\
\hline Don't remember & 0 & 0 \\
\hline Evaluation of SL/I input & & \\
\hline Adequate & 25 & 32.05 \\
\hline Inadequate & 37 & 47.43 \\
\hline Good & 16 & 20.52 \\
\hline Post initial teacher training (NR=291) & & \\
\hline Certificate programs & 14 & 4.81 \\
\hline In service training programs & 32 & 10.99 \\
\hline Certificate programs by the professional & 5 & \\
\hline associations & 71 & 24.4 \\
\hline Field related books & 58 & 19.94 \\
\hline Tv/media & 92 & 31.61 \\
\hline Experience in person & 19 & 6.53 \\
\hline Other &
\end{tabular}

The great majority of the participant teachers (61.59\%) state that between the advantages of being in the same class with their peers at mainstream schools, speech language impaired children's speech is supported by the interaction with their friends Table 4.

Table-4. Teachers' statements about the advantages of speech/language impaired children's inclusion in the mainstream schools.

\begin{tabular}{|c|c|c|}
\hline Teacher statements $(\mathrm{NR}=138)$ & f & $\%$ \\
\hline Their speech is supported by the interaction with their friends. & 85 & 61.59 \\
\hline Their vocabulary increases and they learn different words. & 7 & 5.07 \\
\hline They feel themselves as a part of the society because of not being isolated from the society. & 12 & 8.70 \\
\hline Take their peers as role model in speaking. & 26 & 18.84 \\
\hline They make an effort by regarding speaking as a need. & 8 & 5.80 \\
\hline
\end{tabular}

Participant teachers indicate that if speech language impaired children be together with their peers in the same class at mainstream schools, they may feel themselves incompetent and become introverted (36.36\%), they may be alienated from their peers and they may be offended (28.93\%), they may not be able to find an opportunity to express themselves (4.13\%), they may feel anger because they cannot express themselves (10.74\%) and teachers may not take enough care of them $(17.36 \%)$.

Distinctly, $2.48 \%$ of teachers state that speech language impaired students may be a negative model for the ones who have no speech language impairment problem Table 5.

Table-5. Teachers' statements about the disadvantages of speech/language impaired children's inclusion in the mainstream schools.

\begin{tabular}{|c|c|c|}
\hline Teacher statements $(\mathrm{NR}=121)$ & f & $\%$ \\
\hline They may feel themselves incompetent and become introverted. & 44 & 36.36 \\
\hline They may be alienated from their peers and they may be offended. & 35 & 28.93 \\
\hline They may not be able to find an opportunity to express themselves. & 5 & 4.13 \\
\hline They may feel anger because they cannot express themselves. & 13 & 10.74 \\
\hline Teachers may not take enough care of them. & 21 & 17.36 \\
\hline They may be a negative model for the other students who have no speech language impairment problem. & 3 & 2.48 \\
\hline
\end{tabular}

Information about the special conditions of speech language impaired students that they have in their classes is presented to the $67.32 \%$ of the participant teachers. But $64.08 \%$ of the teachers regard this information as inadequate. While $45.20 \%$ of teachers state that they receive this information from the parents of the students, $17.81 \%$ of them receive it from the special education teacher and $12.33 \%$ of them receive it from the counsellor Table 6.

Also, $76.87 \%$ of them state that it has more advantages than the disadvantages, when is asked to the participant teachers that whether advantages are more than the disadvantages of speech language impaired students' inclusion in mainstream classrooms or not.

When Table 7 is examined, participant teachers state that speech language impaired students may be as successful as their peers in their future education lives (44.76\% possible, $29.37 \%$ quite possible) and they may start slow but they may be able to catch up with their peers (47.22\% possible, $33.33 \%$ quite possible).

The great majority of the participant teachers state that these students may always have academic disadvantage $(65.48 \%)$. Also, while more than half of the participant teachers state that students with SLI may have difficulty in reading $(43.36 \%$ possible, $14.69 \%$ quite possible), a great majority of them state that they may learn topics that do not require speaking more easily (39.17\% possible, $42.65 \%$ quite possible). 


\begin{tabular}{l|c|c} 
Table-6. Sources and adequacy of the information about the students with speech/language impairment. \\
\hline Teacher statements $(\mathbf{n = 1 5 3 )}$ & $\mathbf{f}$ & $\mathbf{\%}$ \\
\hline Information about the students with SLI before they join the class & 103 & 67.32 \\
\hline No & 50 & 32.68 \\
\hline Evaluation of SL/I input & 1 & 0.97 \\
\hline Considerably adequate & 36 & 34.95 \\
\hline Adequate & 66 & 64.08 \\
\hline Inadequate & & \\
\hline Source of information (NR=73) & 13 & 17.81 \\
\hline Special education teacher & 6 & 8.22 \\
\hline Doctor & 9 & 12.33 \\
\hline Counsellor & 4 & 5.48 \\
\hline School management & 2 & 2.74 \\
\hline Counselling and research center & 33 & 45.2 \\
\hline Family & 3 & 4.11 \\
\hline Psychologist & 3 & 4.11 \\
\hline Speech therapist & & \\
\hline
\end{tabular}

Table-7. Teacher predictions about the future education performances of the speech language impaired students in this case study.

\begin{tabular}{l|c|c|c|c|c}
\hline Teacher predictions & No response & Not possible & Probable & Possible & Quite possible \\
\hline They may be as successful as other students & 10 & $0 \%$ & $25.87 \%$ & $44.76 \%$ & $29.37 \%$ \\
\hline They may always have academic disadvantage & 14 & $14.38 \%$ & $65.48 \%$ & $17.27 \%$ & $2.87 \%$ \\
\hline $\begin{array}{l}\text { They may start slow but they may be able to } \\
\text { catch up with their peers }\end{array}$ & 9 & $0.69 \%$ & $18.76 \%$ & $47.22 \%$ & $33.33 \%$ \\
$\begin{array}{l}\text { They may have difficulty in reading and } \\
\text { writing }\end{array}$ & 10 & $2.09 \%$ & $39.86 \%$ & $43.36 \%$ & $14.69 \%$ \\
$\begin{array}{l}\text { They may learn topics that do not require } \\
\text { speaking more easily }\end{array}$ & 10 & $3.49 \%$ & $14.69 \%$ & $39.17 \%$ & $42.65 \%$ \\
\hline
\end{tabular}

\section{Discussion}

The findings of the study reveal that knowledge and awareness levels of preschool teachers about children with speech / language impairment is limited. $46 \%$ of the participants report that they have little or no experience with speech/language impaired children and do not feel themselves adequate in teaching children with severe language problems. Nearly half of the teachers (49\%) indicate that they have not received any lectures about this group of children in their education life. Teachers' most frequently used sources of information to improve their knowledge levels about speech and language disorders are reported as media (19.93\%) and related books (24.40\%). This result may be related to newness of speech and language therapy field in Turkey and the low average education years and ages of the participant teachers.

Although speech language therapy is a new field in Turkey, the number of people who are diagnosed with speech and language disorders are high. So, conducting workshops including evidence-based practice, teaching and learning about children with speech and language disorders may be fruitful to improve the knowledge and skills of teachers in Turkey. These workshops may offer opportunities to the participants to learn about the resources and classroom strategies that are proven successful in teaching students with speech and language disorders.

Another interesting finding of the study is that $32.68 \%$ of the teachers in this study are not informed by parents, special education teachers or school counselor, about the specific needs of the children with speech and language disorders. The collaboration has many advantages like to transfer and share knowledge and skills that are learned in the therapy settings to the school environment in which children spend most of their time and to have consistency in the approaches that meet the demands of both curriculum and therapy (Tollerfield, 2003; Wright and Kersner, 2004). Although routine collaboration between health and education professions is a "must" for the treatment of these disorders, most of the time, this unity is difficult to achieve due to different attitudes of the sectors to practicing, staff training or to the methods that are used to determine the effectiveness of services (McCartney, 2002). Studies show that although both teachers and SLTs know the importance of collaboration (Wright and Kersner, 1999; Lindsay and Dockrell, 2000; Antoniazzi et al., 2010) both groups recognize the difficulties in doing so (Law et al., 2000) because of the factors like lack of communication and lack of time to engage in collaborative discussions or the different priorities of the two professional groups (Wright and Kersner, 1999; Hartas, 2004; Wright and Kersner, 2004) Duties of the school counsellors like sharing information between the families and teachers that support the development of the students with special education needs, are laid down by the laws (Turkish Republic Official Gazzette, 2018). Ideally, an approach in which health professionals understand and learn about the curriculum being taught by teachers in schools and combining the skills of teachers, speech/language therapists and parents, may be the best way to help the children with speech and language disorders. To achieve this, informative handouts may be prepared for the both groups about the roles of the other professions in the intervention team of speech and language disorders.

$85.60 \%$ of the teachers think that it is possible or quite possible that children with speech and language disorders may always have academic disadvantage. A vast majority of the participants (97.9\%) also think that it is possible or quite possible that they may have difficulty in reading and writing. This result is in line with the results of the recent studies which show that speech and language disorders in early period may result in reading disability or language disorders (Lyytinen et al., 2005; Puolakanaho et al., 2008; Rescorla, 2009). In this regard, preschool teachers' knowledge levels on this subject may be a good starting point for future workshops. By this way, most of the children who are at risk of these disorders may be diagnosed as early as possible and may have the advantage of early intervention. 


\section{Limitations}

There are some limitations in this study. This study is limited to the teachers working in kindergarten in İzmit. The research findings were collected in the fall semester of 2018-2019 academic year. Future studies examining teachers' knowledge and awareness levels in specific disorders like stuttering or articulation disorders with larger number of participants may also be fruitful to identify and determine the specific needs of the teachers.

\section{Conclusions}

Knowledge of the preschool teachers about speech and language disorders is essential and the first step for ensuring the best academic, social and psychological well-being of this growing population of children. Learning about training methods for naturalistic strategies that can be used in classroom settings and integrating these strategies throughout the school day is thought to be one of the key elements for effective classroom intervention. Because of the young age of the Speech and Language Therapy profession in Turkey, specific workshops or informative videos prepared for preschool teachers about speech and language disorders may offer opportunities to learn about the resources and classroom strategies that are proven successful in teaching students with speech and language disorders in Turkey.

\section{Implications for School Health}

Preschool teachers play a key role in identifying and supporting children with speech and language disorders in the classroom. Identifying signs of these disorders in the classroom and consulting and collaborating with a speech and language therapists can prevent labeling and long term academic and psychosocial problems. Speech and language therapy is a new and developing area in Turkey. So, most of the teachers do not have opportunity to learn about speech and language disorders and the role and responsibilities of the speech and language therapist in these disorders. We need to train teachers about these disorders and the profession via different channels to promote collaboration and effective interventions. Most of the teachers do not receive any course about this group in the university courses. Speech and language disorders should also be recognized by the public and policy makers and included as part of the national preschool teacher training curriculum. Specific workshops conducted for preschool teachers about this group can also be an alternative to access related knowledge.

\section{References}

Antoniazzi, D., P. Snow and V. Dickson-Swift, 2010. Teacher identification of children at risk for language impairment in the first year of school. International Journal of Speech-Language Pathology, 12(3): 244-252.Available at: https://doi.org/10.3109/17549500903104447.

ASHA, 2018. Spoken Language Disorders Incidence and Prevalence. Available from https://www.asha.org/PRPSpecificTopic.aspx?folderid=8589935327\&section=Incidence_and_Prevalence.

Aydın, A.U. and G. Tura, 2018. Evaluation of teacher candidates' attitudes and knowledge about language and speech disorders in children. Kocaeli University Journal of Education, 1(1): 13-22.Available at: https://doi.org/10.33400/kuje.425174.

Blackorby, J. and M. Wagner, 1996. Longitudinal postschool outcomes of youth with disabilities: Findings from the national longitudinal transition study. Exceptional Children, 62(5): 399-413.Available at: https://doi.org/10.1080/14015430500342384.

Botting, N. and G. Conti-Ramsden, 2000. Social and behavioural difficulties in children with language impairment. Child Language Teaching and Therapy, 16: 105-120.Available at: https://doi.org/10.1177/026565900001600201.

Boyle, J., E. McCartney, A. O'HARE and J. Law, 2010. Intervention for mixed receptive-expressive language impairment: A review. Developmental Medicine \& Child Neurology, 52(11): 994-999.Available at: https://doi.org/10.1111/j.1469-8749.2010.03750.x.

Buyukozturk, S., E.K. Kilic, O. Akgun, S. Karadeniz and F. Demirel, 2009. Scientific research methods. 4th Edn., Ankara: Pegem A Publishing.

Catts, H.W., 1994. The early identification of language-based reading disabilities. Language, Speech, and Hearing Services in Schools, 28(1): 86-89.Available at: https://doi.org/10.1044/0161-1461.2801.86.

Committee on the Evaluation of the Supplemental Security Income (SSI) Disability Program for Children with Speech Disorders and Language Disorders, 2016. Board on the health of select populations; board on children, youth, and families; institute of medicine; division of behavioral and social sciences and education; national academies of sciences, engineering, and medicine; rosenbaum s, simon p, editors. Speech and language disorders in children: Implications for the social security administration's supplemental security income program. Washington (DC): National Academies Press (US); 2016 Apr 6. 1, Introduction.

Conti-Ramsden, G. and K. Durkin, 2012. Language development and assessment in the preschool period. Neuropsychology Review, 22(4): $384-401$.

Felsenfeld, S., P.A. Broen and M. McGue, 1994. A 28-year follow-up of adults with a history of moderate phonological disorder: Educational and occupational results. Journal of Speech, Language, and Hearing Research, 37(6): 1341-1353.Available at: https://doi.org/10.1044/jshr.3706.1341.

Hartas, D., 2004. Teacher and speech-language therapist collaboration: Being equal and achieving a common goal? Child Language Teaching and Therapy, 20(1): 33-54.Available at: https://doi.org/10.1191/0265659004ct262oa.

Karasar, N., 2010. Scientific research methods. 21 th Edn., Ankara: Nobel Publishing.

Law, J., G. Lindsay, N. Peacey, M. Gascoigne, N. Soloff, J. Radford and L. Fitzgerald, 2000. Provision for children with speech and language needs in England and Wales: Facilitating communication between education and health services. Nottingham, UK: Department for Education and Employment.

Lindsay, G. and J. Dockrell, 2000. The behaviour and self-esteem of children with specific speech and language difficulties. British Journal of Educational Psychology, 70(4): 583-601.Available at: https://doi.org/10.1348/000709900158317.

Lyytinen, P., K. Eklund and H. Lyytinen, 2005. Language development and literacy skills in late-talking toddlers with and without familial risk for dyslexia. Annals of Dyslexia, 55(2): 166-192.Available at: https://doi.org/10.1007/s11881-005-0010-y.

Mavis, I., B. Togram and A. Akyuz-Togram, 2005. Pre-school and elementary school teachers' views on language and speech disorders.

McCartney, E., 2002. Cross-sector working: Speech and language therapists in education. Journal of Management in Medicine, 16(1): 6777.Available at: https://doi.org/10.1108/02689230210428634.

McLeod, S. and D.H. McKinnon, 2007. Prevalence of communication disorders compared with other learning needs in 14500 primary and secondary school students. International Journal of Language \& Communication Disorders, 42(sup 1): 37-59.

Puolakanaho, A., T. Ahonen, M. Aro, K. Eklund, P.H. Leppänen, A.-M. Poikkeus, A. Tolvanen, M. Torppa and H. Lyytinen, 2008. Developmental links of very early phonological and language skills to second grade reading outcomes: Strong to accuracy but only minor to fluency. Journal of Learning Disabilities, 41(4): 353-370.Available at: https://doi.org/10.1177/0022219407311747.

Rescorla, L., 2009. Age 17 language and reading outcomes in late-talking toddlers. Journal of Speech Language and Hearing Research, 48(2): 459-472.Available at: https://doi.org/10.1044/1092-4388(2005/031).

Sadler, J., 2005. Knowledge, attitudes and beliefs of the mainstream teachers of children with a preschool diagnosis of speech/language impairment. Child Language Teaching and Therapy, 21(2): 147-163.Available at: https://doi.org/10.1191/0265659005ct2860a. 
Schuele, C.M., 2004. The impact of developmental speech and language impairments on the acquisition of literacy skills. Mental Retardation and Developmental Disabilities Research Reviews, 10(3): 176-183.Available at: https://doi.org/10.1002/mrdd.20014.

Snowling, M.J., J.W. Adams, D.V. Bishop and S.E. Stothard, 2001. Educational attainments of school leavers with a preschool history of speech-language impairments. International Journal of Language \& Communication Disorders, 36(2): 173-183.Available at: https://doi.org/10.1080/13682820120976.

Tollerfield, I., 2003. The process of collaboration within a special school setting: An exploration of the ways in which skills and knowledge are shared and barriers are overcome when a teacher and speech and language therapist collaborate. Child Language Teaching and Therapy, 19(1): 67-84.

Topbas, S.A., 2006. Turkish perspective on communication disorders. Logopedics Phoniatrics Vocology, 31(2): 76-88.

Turkish Republic Official Gazzette, 2018. Curriculum of national educational services. Available Ni_Rehbrlk_Yon.Pdf. Available from https://orgm.meb.gov.tr/meb_iys_dosyalar/2017_11/10113305_ye [Accessed October 8].

Wright, J.A. and M. Kersner, 1999. Teachers and speech and language therapists working with children with physical disabilities: Implications for inclusive education. British Journal of Special Education, 26(4): 201-205.Available at: https://doi.org/10.1111/1467-8527.00139.

Wright, J.A. and M. Kersner, 2004. Short-term projects: The standards fund and collaboration between speech and language therapists and teachers. Support for Learning, 19(1): 19-23.Available at: https://doi.org/10.1111/j.0268-2 141.2004.00313.x. 